\title{
Ácidos húmicos de vermicomposto estimulam o crescimento in vitro de plântulas de Cattleya warneri (Orchidaceae)
}

Vermicompost humic acid stimulates in vitro growth of Cattleya warneri (Orchidaceae) seedlings

\author{
Maria Alice Costa da Silva ${ }^{1}$, Wolmen Oliveira dos Santos ${ }^{1}$, Nágila Teixeira Simoura ${ }^{1}$, Juliétty Angioletti \\ Tesch ${ }^{1}$, Katherine Fraga Ruas ${ }^{1}$, Carlos Moacir Colodete ${ }^{1}$, Fernanda Pavesi Tannure ${ }^{1}$, Juliano de Oliveira \\ Barbirato ${ }^{1}$, Alessandro Coutinho Ramos ${ }^{2} \&$ Leonardo Barros Dobbss ${ }^{1,3}$
}

\begin{abstract}
Resumo
A Cattleya warneri var. concolor (Orchidaceae) é uma planta epífita ameaçada de extinção com potencial econômico ornamental. Este trabalho objetivou estudar o crescimento in vitro de plântulas da espécie supracitada em diferentes doses de ácidos húmicos $(\mathrm{AH})$ isolados de vermicomposto. A avaliação do crescimento promovido pelos $\mathrm{AH}$ foi realizada por meio das variáveis número de folhas e raízes, massas frescas e secas das folhas e de raízes e de estimativas da atividade da enzima $\mathrm{H}^{+}$-ATPase. Os resultados obtidos indicaram que o material húmico obtido foi capaz de incrementar o crescimento da planta estudada e promover estímulos associados à atividade da referida enzima. Estabelece-se assim, um bioestimulante eficiente visando a produção de mudas de Cattleya warneri var. concolor.

Palavras-chave: Crescimento vegetal, orquídea, substâncias húmicas.
\end{abstract}

\begin{abstract}
Cattleya warneri var. concolor (Orchidaceae) is an endangered epiphyte plant with ornamental economic potential. In this research, we have studied in vitro growth of $C$. warneri's seedlings at different doses of humic acids isolated from vermicompost. The evaluation on growth promoted by $\mathrm{AH}$ was performed using variables number of leaves and roots, fresh and dry weight of leaves and roots and estimates of the $\mathrm{H}^{+}$-ATPase enzyme activity. The results indicated that the humic material obtained was able to increase the growth of the studied plant and promoting stimuli associated with the said enzyme activity. It is thus established, an efficient biostimulant aimed at producing Cattleya warneri var. concolor seedlings.
\end{abstract}

Key words: Plant growth, orchid, humic substances.

\section{Introdução}

A família Orchidaceae compreende aproximadamente $10 \%$ de todas as angiospermas existentes e possui distribuição cosmopolita, desempenhando um importante papel na manutenção da diversidade biológica (Ackerman 1998; Pinheiro et al. 2004). É considerada refletora nas dinâmicas dos processos ecológicos, como também, potencialmente bioindicadora na avaliação de impactos da poluição atmosférica nos ecossistemas, devido a sua capacidade de acumular elementos químicos (Elias et al. 2006).
Por outro lado, além do Brasil possuir um rico patrimônio de orquídeas, representado por 190 gêneros e 2.300 espécies, existe uma ameaça iminente de decrécimo desse número por consequência do processo de extinção (Pansarin \& Pansarin 2011). Vários são os motivos para o desaparecimento destas orquídeas do ambiente natural, na sua grande maioria relacionados às atividades antropogênicas (Pansarin \& Pansarin 2011). As coletas indiscrimidadas ocorrem, possívelmente pelo seu elevado valor econômico no agronegócio florícola (Zanenga-Godoy \&

\footnotetext{
${ }^{1}$ Universidade Vila Velha - UVV, Complexo Biopráticas, Laboratório de Ecologia da Matéria Orgânica - LEMO, R. Comissário José Dantas de Melo, 21, 29101-770, Boa Vista, Vila Velha, ES, Brasil.

${ }^{2}$ Universidade Estadual do Norte Fluminense Darcy Ribeiro (UENF), Centro de Biociências e Biotecnologia, Av. Alberto Lamego 2000, 28013-602 Horto, Campos dos Goytacazes, RJ, Brasil.

${ }^{3}$ Autor para correpondência: leonardo.dobbss@uvv.br.
} 
Costa 2003). Segundo o último relatório divulgado pelo Ministério do Meio Ambiente (Instrução Normativa, ${ }^{\circ} 6$ de 23 de Setembro de 2008), a espécie Cattleya warneri var. concolor, nativa do Bioma Mata Atlântica, está entre as 34 orquídeas ameaçadas em extinção no Brasil (MMA 2014).

São escassos na literatura estudos que tenham se dirigido à reintrodução de orquídeas após bioestimulação húmica in vitro. Sendo assim, a utilização de materiais orgânicos visando o estímulo ao crescimento de plântulas de orquídeas, torna-se uma ferramenta fundamental para sua reintrodução, após início de processo de extinção (Zeng et al. 2012). A germinação de sementes de orquídeas assimbióticamente, com posterior propagação in vitro da cultura em meios contendo diferentes frações orgânicas torna-se útil para a articulação de programas que visem à reintrodução de espécies nativas (Martini et al. 2001). Trabalhos utilizando-se substâncias húmicas ( $\mathrm{SH}$ ) em substratos para o crescimento e desenvolvimento de plântulas já mostraram eficiência para o gênero botânico Cymbidium pertencente à família Orchidaceae (Baldotto et al. 2014), bem como para outras espécies vegetais, principalmente de interesse agrícola, tais como: milho (Zea mays), arabidopsis (Arabdopsis thaliana), tomate (Solanum licopersicum) e arroz (Oryza sativa) (Canellas et al. 2002; Dobbss et al. 2007; Dobbss et al. 2010; Ramos et al. 2015).

A vermicompostagem é a mudança da matéria orgânica, resultado da ação combinada de minhocas e dos microrganismos que vivem em seu trato digestivo, aumentando assim, a velocidade de decomposição dos resíduos orgânicos (Albanell et al. 1988). O vermicomposto difere do composto convencional, dentre outras características, pela maior estabilização dos resíduos orgânicos que, através do trato digestivo das minhocas sofre reações enzimáticas, convertendo rapidamente os resíduos em grande quantidade de substâncias húmicas, como humina, ácidos fúlvicos e húmicos (Almeida 1991).

As SH são bioestimulantes (Trevisan et al. 2010) e se apresentam também como fonte de nutrientes para as plantas, disponibilizando carbono (C), nitrogênio (N), fósforo (P) e enxofre (S). Geralmente as SH são fracionadas em função de sua solubilidade. Os ácidos húmicos (AH) são particularmente definidos operacionalmente como a fração das SH solúveis que precipita pela acidificação do extrato alcalino oriundo da primeira etapa da extração convencional (Canellas \& Santos 2005).
Os AH apresentam elevada atividade de estimulação no crescimento de plântulas quando usados em concentrações relativamente pequenas (Nardi et al. 2007; Aguiar et al. 2013). Estas substâncias estão naturalmente presentes no solo, contribuindo direta ou indiretamente na adaptabilidade ambiental e no metabolismo do C (Nardi et al. 2007). Além disso, benefícios adicionais são relatados, como aumento da promoção de crescimento radicular (Nardi et al. 2002), através da ativação e expressão das $\mathrm{H}^{+}$ATPases, e maior transporte (influxo e efluxo) de íons (Zandonadi et al. 2013; Ramos et al. 2015), apresentando funções similares ao do fitormônio auxina (Dobbss et al. 2010).

Desta forma, o objetivo desse trabalho foi avaliar o crescimento in vitro de plântulas de Cattleya warneri var. concolor em diferentes doses de $\mathrm{AH}$ isolados de vermicomposto, visando posterior viabilidade do repovoamento dessa orquídea ao seu hábitat natural e paralelamente fornecer plantas com alto vigor vegetativo ao mercado de ornamentais reduzindo a procura por exemplares provenientes do ambiente natural.

\section{Material e Metodos}

Obtenção, isolamento e purificação das substâncias húmicas

As substâncias húmicas (SH) foram extraídas e purificadas conforme descrito por Stevenson (1994) e Canellas et al. (2002). Utilizou-se como material orgânico uma amostra de $200 \mathrm{~g}$ de vermicomposto adquirido comercialmente, que foi seca ao ar e peneirada (peneira de malha de $2 \mathrm{~mm}$ ). A extração da SH foi realizada utilizando-se extrator $\mathrm{NaOH} 0,5 \mathrm{~mol} \mathrm{~L}^{-1}$, na razão vermicomposto:solvente de 1:10 (m:v) em atmosfera inerte de $\mathrm{N}_{2}$. A separação dos $\mathrm{AH}$ foi alcançada com a redução do $\mathrm{pH}$ da solução até $1-1,5 \mathrm{com}$ extrator $\mathrm{HCl}$ a $6 \mathrm{~mol} \mathrm{~L}^{-1}$ seguido de centrifugação a $5000 \mathrm{~g}$ por 20 minutos. A redissolução e precipitação foram repetidas três vezes. Em seguida, adicionou-se $200 \mathrm{~mL}$ da solução de ácido fluorídrico (HF)/clorídrico (HCl) a 0,3 mol $\mathrm{L}^{-1}$, submetendo as amostras à agitação durante 8 horas. Após centrifugação a 5000 g por 15 minutos, o precipitado (AH) foi lavado (4 vezes) com água deionizada até teste negativo com $\mathrm{AgNO}_{3}$, dialisado contra água deionizada, utilizando-se membranas com poros de 1000 Da (Thomas Scientific, Inc) e secos por liofilização. 


\section{Composição elementar}

A composição elementar dos AH foi obtida após análise em analisador elementar automático (CHNS - 932, Leco, Alemanha) com amostras de $4 \mathrm{mg}$ de $\mathrm{AH}$ em triplicata. $\mathrm{O}$ teor de oxigênio foi obtido por diferença [\%O = $100-(\% \mathrm{C}+\% \mathrm{H}+\% \mathrm{~N})]$ e o de cinzas pela incineração de $50 \mathrm{mg}$ dos materiais húmicos por $700^{\circ} \mathrm{C}$ durante 8 horas. Após a obtenção dos valores de $\mathrm{C}, \mathrm{H}, \mathrm{N}$ e O (em \%) foram calculadas as relações atômicas (C/N; H/C e O/C).

Bioatividade dos ácidos húmicos Ensaio de dose resposta - Crescimento in vitro de plântulas de Cattleya warneri var. concolor (Orchidaceae) e o tratamento com os materiais húmicos

Utilizou-se como fonte de explantes, plântulas de orquídea Cattleya warneri var. concolor, medindo aproximadamente $1 \mathrm{~cm}$, obtidas por meio da germinação assimbiótica in vitro, seguindo a metodologia proposta por Dorneles \& Trevelin (2011). O meio de cultura básico utilizado foi constituído pelos sais e vitaminas de Knudson $\mathrm{C}$ modificado que é usualmente empregado na micropropagação de orquídeas (Soares et al. 2009), acrescido de carvão ativado (2,5 $\left.\mathrm{g} \mathrm{L}^{-1}\right)$, sacarose (20 $\left.\mathrm{g} \mathrm{L}^{-1}\right)$, polpa de banana nanica (Musa paradisiaca) $\left(150 \mathrm{~g} \mathrm{~L}^{-1}\right)$ e ágar-ágar $\left(6 \mathrm{~g} \mathrm{~L}^{-1}\right)$. Após a mistura de todos os nutrientes, o $\mathrm{pH}$ foi ajustado para $5,7 \pm 0,1$ antes da autoclavagem, que foi realizada a $121^{\circ} \mathrm{C}$ e $1 \mathrm{~atm}$, por 20 minutos.

O cultivo foi realizado em frascos de vidro de $250 \mathrm{~mL}$ de capacidade contendo $50 \mathrm{~mL}$ do meio de cultura. Foram acondicionados quatro explantes em cada frasco, sendo os tratamentos descritos na (Tab. 1). Cada tratamento possuía cinco repetições. Utilizou-se o meio de Knudson C modificado, como supracitado. A adição das diferentes concentrações de AH foi realizada com o auxílio de seringa graduada estéril e filtro milipore ${ }^{\circledR}(0,45 \mu \mathrm{m}$, Sartorius).
Em ambos os experimentos (ensaio de doses e com a dose ótima), as plântulas foram mantidas em sala de crescimento à temperatura de $25 \pm 2^{\circ} \mathrm{C}$, fotoperíodo de 16 horas e radiação luminosa de 60 $\mu \mathrm{mol}$ de fótons $\mathrm{m}^{-2} \mathrm{~s}^{-1}$. No primeiro experimento foi obtida uma curva de resposta para a massa fresca e seca das raízes e folhas, utilizando-se as concentrações de 0 ; 0,5; 1; 2; 4 e 8 mM de $C$ do AH. A Tabela 1 mostra a descrição dos tratamentos desse experimento. Após o procedimento da análise de regressão e obtenção da melhor dose de AH um novo experimento foi montado desta vez utilizandose a dose recomendada.

Após a obtenção da dose ótima recomendada através das médias dos pontos de inflexão pela derivação das equações de regressão (Tab. 3), foram avaliadas as seguintes características: número de folhas, número de raízes, massa fresca e massa seca das folhas e das raízes sempre realizando-se comparações entre o tratamento controle e e a melhor dose de AH. A massa seca foi obtida após secagem do material em estufa a $60^{\circ} \mathrm{C}$, até massa constante.

Medida de acidez em solução possivelmente associada à atividade dos $\mathrm{AH}$ sobre as $\mathrm{H}^{+}$-ATPases

A estimativa da atividade da $\mathrm{H}^{+}$-ATPase foi avaliada pela medição de acidez de soluções de cultivo contendo plântulas de Cattleya warneri var. concolor tratadas ou não com AH de vermicomposto seguindo a metodologia de Aguiar et al. (2013). Utilizou-se a melhor dose de AH $(4,16 \mathrm{mM}$ de C $\mathrm{L}^{-1}$ ) obtida no ensaio preliminar de dose resposta. Nesse experimento, foi utilizado o meio mínimo $\left(\mathrm{CaCl}_{2} 2 \mathrm{mM}\right)$ que é extensamente utilizado em trabalhos onde se quer testar somente a influência de um determinado material húmico (Canellas et al. 2002; Dobbss et al. 2010 e Ramos et al. 2015). Esse procedimento foi realizado a fim de evitar

Tabela 1 - Descrição dos tratamentos oferecidos ao meio de cultura contendo plântulas Cattleya warneri var. concolor crescidas in vitro por 90 dias com adição de diferentes doses de $\mathrm{AH}$.

Table 1 - Description of the treatments offered to the culture medium containing the seedlings Cattleya warneri var. concolor grown in vitro for 90 days with the addition of various doses of HA.

\footnotetext{
T0 - cultivo por 90 dias sem adição de ácidos húmicos

T1 - cultivo por 90 dias com adição de $0,5 \mathrm{mM}$ de $\mathrm{C} \mathrm{AH}$ aos 15 dias de cultivo

T2 - cultivo por 90 dias com adição de 1,0 mM de C AH aos 15 dias de cultivo

T3 - cultivo por 90 dias com adição de 2,0 mM de C AH aos 15 dias de cultivo

T4 - cultivo por 90 dias com adição de 4,0 mM de C AH aos 15 dias de cultivo

T5 - cultivo por 90 dias com adição de 8,0 mM de C AH aos 15 dias de cultivo
} 
qualquer influência dos nutrientes, que poderiam funcionar de maneira sinergética com as $\mathrm{AH}$, estimulando o desenvolvimento radicular e o metabolismo das plântulas. Dez plântulas foram submetidas ao tratamento com e sem AH em beckeres de $100 \mathrm{~mL}$ durante 48 horas. Após este período, foram transferidas para um recipiente com $50 \mathrm{~mL}$ de uma solução de $\mathrm{CaCl}_{2} 2 \mathrm{mM}$ a pH 7 por 140 minutos.

A medida da acidez $(\mathrm{pH})$ da solução de $\mathrm{CaCl}_{2}$ foi medida com auxílio de um pHmetro durante o mesmo período (140 minutos). As raízes foram então secas em estufa de ar forçado, e a quantidade de $\mathrm{H}^{+}$foi expressa em extrusão de $\mathrm{H}^{+}$por grama de massa seca de raízes, podendo-se associar, portanto, ao gradiente de prótons gerado pela atividade da $\mathrm{H}^{+}$-ATPase.

\section{Análise Estatística}

Para todas as variáveis analisadas foi realizada a análise de variância, para verificar o efeito do tratamento em relação às respostas. Os dados foram analisados utilizando-se o delineamento inteiramente casualizado (DIC), com 2 tratamentos (controle e a melhor dose de ácido húmico), com cinco repetições cada. Cada repetição foi composta por cinco frascos, sendo a unidade experimental constituída por um frasco contendo 4 explantes.

Com relação ao experimento de dosereposta procedeu-se a análise de regressão, e os modelos apresentados foram aqueles em que melhor se ajustaram. Os dados de regressão foram normais e suas significâncias e de seus coeficientes foram verificadas pelo teste $\mathrm{F}$ $(p<0,05)$ e pelo teste $t(p<0,05)$, respectivamente. $\mathrm{O}$ ajuste de regressão foi efetuado pelo coeficiente ajustado $\left(\mathrm{R}^{2}\right)$. Tanto a obtenção da melhor dose de $\mathrm{AH}$ quanto as respostas sobre a morfologia das plântulas foram avaliadas ao final de 90 dias.

Para a estimativa da atividade da $\mathrm{H}^{+}$ATPase, foi utilizado DIC, com dois tratamentos (controle e melhor dose de $\mathrm{AH}$ ) contendo dez plantas cada e 3 repetições. Todos os dados foram analisados com o emprego do programa estatístico SISVAR (Ferreira 2011) e as diferenças entre as médias dos tratamentos controle e AH foram comparadas pelo teste de Tukey a 5\% de probabilidade.

\section{Resultados e Discussão}

Análise elementar e relações atômicas dos ácidos húmicos

A composição elementar e as razões atômicas dos $\mathrm{AH}$ isolados de vermicomposto estão apresentadas na Tabela 2. As características elementares são freqüentemente utilizadas para relacionar características químicas dos AH com a gênese e/ou propriedades da origem de extração (Stevenson 1994) e neste trabalho foram usadas para obtenção das doses de $\mathrm{AH}$ (em mM de carbono $\mathrm{L}^{-1}$ ) que foram utilizadas nos experimentos preliminares de dose resposta.

Stevenson (1994) sugeriu que quando a razão $\mathrm{C} / \mathrm{N}$ está entre 10 e 12, é um indicativo de intensa estabilidade biológica. Conforme mostrado na Tabela 2 o AH isolado de vermicomposto utilizado nesse trabalho está dentro da faixa sugerida, indicativo de material húmico estável. Com relação a razão atômica $\mathrm{H} / \mathrm{C}$, valores superiores a 1, indicam maior contribuição de componentes alifáticos (alifaticidade) das SH (Steelink 1985; Canellas \& Santos 2005), indicando também a presença de material com característica apolar nos $\mathrm{AH}$, típicos de $\mathrm{SH}$ pouco evoluídas estruturalmente. Neste estudo a natureza alifática foi bem evidente, já o $\mathrm{AH}$ apresentou razão H/C superior a 1 (Tab. 2). Por sua vez, valores da relação $\mathrm{O} / \mathrm{C}$ maiores que 0,5 , conforme verificado para o $\mathrm{AH}$ utilizado nesse trabalho, indica presença de maior quantidade de grupos funcionais oxigenados como $\mathrm{COOH}$ e carboidratos (Fontana 2010). Em um trabalho realizado por Miranda et al. (2007), foi verificado resultados semelhantes ao encontrado no presente trabalho quanto às relações $\mathrm{H} / \mathrm{C}$ e $\mathrm{O} / \mathrm{C}$.

Tabela 2. Composição elementar (livre de água e cinzas) e relações atômicas das substâncias húmicas estudadas. Table 2. Elemental composition (free of water and ash) and atomic ratios of humic acids.

\begin{tabular}{|c|c|c|c|c|c|c|c|}
\hline \multirow{3}{*}{$\begin{array}{l}\text { AH } \\
\text { Vermicomposto }\end{array}$} & C & $\mathbf{H}$ & $\mathbf{N}$ & O & \multicolumn{3}{|c|}{ Relações Atômicas } \\
\hline & \multicolumn{4}{|c|}{$\%$} & $\mathbf{C} / \mathbf{N}$ & $\mathbf{H} / \mathbf{C}$ & $\mathrm{O} / \mathrm{C}$ \\
\hline & 44,60 & 4,51 & 4,75 & 46,14 & 10,95 & 1,21 & 0,78 \\
\hline
\end{tabular}


Atividade Biológica dos Ácidos Húmicos

As curvas de regressão quadrática para a massa fresca e massa seca das folhas e raízes das plântulas de Cattleya warneri var. concolor tratadas com diferentes doses dos ácidos húmicos se encontram ilustradas na Figura 1. A Tabela 3 indica o modelo de dose-resposta, mostrando a dose ideal do material húmico estudado. Conforme pode ser observado na Tabela 3, os valores das médias das doses ótimas de $\mathrm{AH}$ variaram de 3,98 a 4,25 $\mathrm{mM}$ de $\mathrm{C} \mathrm{L}^{-1}$ respectivamente para as massas seca e fresca de raízes. No trabalho de Pinheiro et al. (2010), para mudas de eucalipto, a melhor dose para o estímulo do diâmetro dos caules foi de 4,30 mg $\mathrm{C} \mathrm{L}^{-1}$ de AH. Já Aguiar et al. (2009) verificaram doses em torno de $5 \mathrm{mg} \mathrm{C} \mathrm{L}^{-1}$ de AH para o número de raízes laterais de Arabidopsis thaliana. Assim, é importante destacar que o sucesso da aplicação dos ácidos húmicos sobre vegetais, depende de estudos preliminares que definam a dose ótima para cada espécie (Baldotto \& Baldotto 2014).
De acordo com a Figura 2, os AH isolados de vermicomposto apresentaram habilidade para estimular o crescimento de plântulas de Cattleya warneri var. concolor. A adição de $\mathrm{AH}$ ao meio de cultura proporcionou um incremento de 81 e $159 \%$ em relação ao controle (100\%), para a massa fresca das folhas e das raízes respectivamente (Figura 2a,b). Resultado semelhante foi encontrado por Conceição et al. (2008) onde foi verificado que a adição de ácidos húmicos de vermicomposto incrementou em $34 \%$ a massa da matéria fresca das raízes de plantas de milho em relação ao tratamento controle. Já Bernardo et al. (2011) observou aumentos da massa fresca das raízes de tomateiro quando utilizou húmus como substrato para o crescimento vegetal.

$\mathrm{O}$ maior efeito em magnitude dos AH sobre as plântulas de Cattleya warneri var. concolor foi observado na massa fresca das raízes, onde foram observados acréscimos de até $159 \%$ em relação ao controle (Fig. 2b). Esse aumento, segundo Vaughan \& Malcolm (1985), pode estar relacionado ao forte estímulo das substâncias húmicas sobre
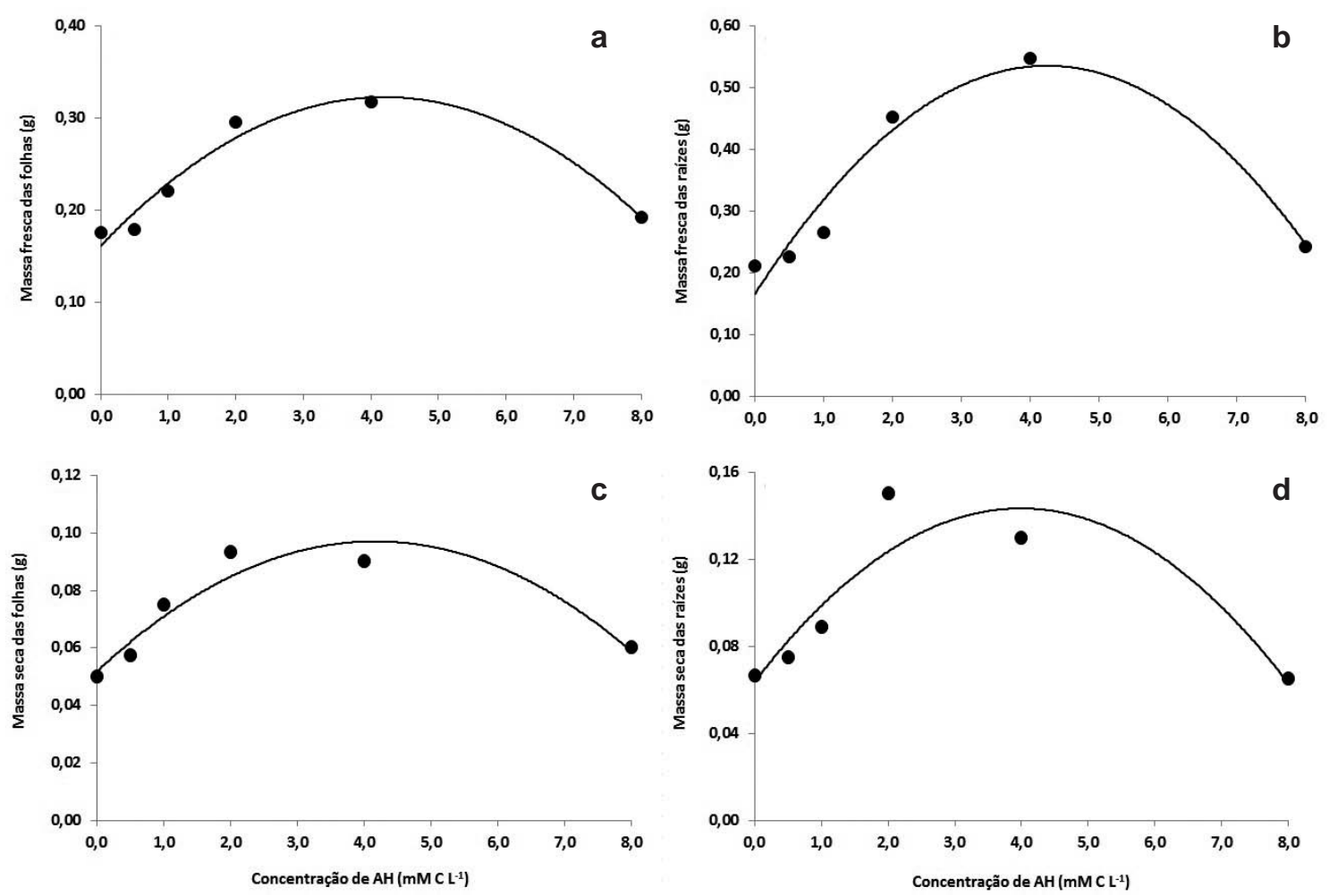

Figura 1-Curvas de regressão quadrática para a massa fresca das folhas e raízes (a,b) e massa seca das folhas e raízes (c,d). Figure 1 - Quadratic regression curves for leaves and roots fresh weight mass $(\mathrm{a}, \mathrm{b})$ and leaves and roots dry weight $(\mathrm{c}, \mathrm{d})$. 
Tabela 3 - Modelo de dose-resposta, coeficiente de correlação $\left(\mathrm{R}^{2}\right)$, desvio-padrão da regressão (DP), número de unidades que integram a amostra (n), nível de significância da regressão (valor-p) e ponto de inflexão (dose ótima) para a massa fresca das folhas (MFF), massa fresca das raízes (MFR), massa seca das folhas (MSF) e massa seca das raízes (MSR) de plântulas de Cattleya warnery var. concolor após 90 dias em tratamento com AH.

Table 3 - Dose-response model, correlation coefficient $\left(\mathrm{R}^{2}\right)$, standard deviation of regression (SD), number of units included in the sample (n) regression significance level ( $p$-value) and inflection point (optimal dose) for leaves fresh weight (LFW), roots fresh weight (RFW), leaf dry weight (LDW) and root dry weight (RDW) seedlings of Cattleya Warnery var. concolor after 90 days in HA treatment.

\begin{tabular}{lcccccc}
\hline $\begin{array}{l}\text { Material } \\
\text { húmico }\end{array}$ & $\begin{array}{c}\text { Equação } \\
\left(\mathbf{y}=\mathbf{b} 2 \mathbf{x}^{2}+\mathbf{b} 1 \mathbf{x}+\mathbf{b} \mathbf{0}\right)\end{array}$ & $\mathbf{R}^{2}$ & $\begin{array}{c}\text { Desvio } \\
\text { Padrão }\end{array}$ & $\mathbf{N}$ & $\boldsymbol{p}$ & $\begin{array}{c}\text { Dose ideal } \\
(\mathbf{d} \mathbf{x} / \mathbf{d y}): \mathbf{b} \mathbf{+}+\mathbf{2}(\mathbf{b} \mathbf{2}) \mathbf{x}=\mathbf{0}\end{array}$ \\
\hline MFF & $\mathrm{y}=-0,0091 \mathrm{x}^{2}+0,0768 \mathrm{x}+0,1609$ & 0,9500 & 1,17 & 20 & $<0,0001$ & 4,22 \\
MFR & $\mathrm{y}=-0,0205 \mathrm{x}^{2}+0,1741 \mathrm{x}+0,1655$ & 0,9386 & 1,26 & 20 & $<0,0001$ & 4,25 \\
MSF & $\mathrm{y}=-0,0026 \mathrm{x}^{2}+0,0217 \mathrm{x}+0,0519$ & 0,8981 & 1,68 & 20 & $<0,0001$ & 4,17 \\
MSR & $\mathrm{y}=-0,005 \mathrm{x}^{2}+0,0398 \mathrm{x}+0,0639$ & 0,8346 & 2,84 & 20 & $<0,0001$ & 3,98 \\
MÉDIA & & & & & & 4,16
\end{tabular}

o desenvolvimento radicular (bem mais do que na parte aérea) com concentrações relativamente pequenas de materiais húmicos em solução.

Foram observados incrementos estatisticamente significativos tanto para a massa seca das folhas quanto raízes de Cattleya warneri var. concolor, promovidos por AH (Fig. 2c,d). Nossos dados corroboram com os de Baldotto et al. (2014) no qual foi avaliado o crescimento de orquídea Cymbidium sp. in vitro em resposta à aplicação de $\mathrm{AH}$. No referido estudo os autores revelaram aumentos à massa seca da raiz e da parte aérea das plântulas de Cymbidium sp. com as aplicações das concentrações de $18,75 \mathrm{mmol} \mathrm{L}^{-1}$ de $\mathrm{C}$ de $\mathrm{AH}$ extraídos da compostagem de cama de frango e de 3,77 mmol L-1 de C de AH extraídos de compostagem de esterco bovino, com incrementos em relação ao controle de 21 e 28\%, respectivamente. Doses essas bem maiores do que a utilizada nesse estudo (4,16 $\mathrm{mM}$ de $\mathrm{C} \mathrm{L}^{-1}$ ). Pinheiro et al. (2010) verificaram que concentrações baixas de $\mathrm{AH}$ promovem raízes altamente ramificadas, resultando numa elevada área radicular que pode contribuir para uma absorção mais eficiente de nutrientes. Vaughan \& Malcolm (1985), também notaram efeitos positivos no crescimento radicular e foliar de trigo cultivado em uma solução com a concentração de 50 mg L-1 de $\mathrm{AH}$.

Conforme observado na Figura 2e, houve incremento estatisticamente significativo de $17 \%$ no número de folhas por planta submetidas ao tratamento com $\mathrm{AH}$ em comparação com as plântulas controle (sem adição de AH). Para o número de raízes por planta ocorre incremento ainda maior, quando adicionado $\mathrm{AH}$ ao meio de cultura, proporcionando 32\% em relação às plântulas controle, sendo significativamente superior (Fig. 2f). Esses resultados estão de acordo com os de outros autores que também observaram efeito positivo dos AH no incremento do número de folhas e de raízes após a avaliação do crescimento (Atiyeh et al. 2002) e nutrição mineral de plântulas de tomate (Adani et al. 1998; Türkmen et al. 2004). Da mesma forma, Nikbakht et al. (2008), também observaram aumento dessas variáveis após avaliação do crescimento e nutrição de plantas de Gerbera jamesonii L. cv. Malibu.

Medida da acidez em solução associado à atividade da $\mathrm{H}^{+}$-ATPase

O aumento da acidez por menores valores de $\mathrm{pH}$ da solução foi observado nos tratamentos com AH (Fig. 3a). Nossos resultados corroboram aos de Aguiar et al. (2011), no qual foi observado aumento na acidez das soluções contendo plântulas de milho que haviam sido tratadas com AH extraídos de vermicompostos em diferentes estádios de maturação. Conforme pode ser observado na Figura 3b foi nítido o aumento da extrusão de prótons pelas raízes de plântulas de Cattleya warneri var. concolor tratadas por 48 horas com $\mathrm{AH}$, reflexo da redução dos valores dos valores de $\mathrm{pH}$ medidos durante 140 minutos na solução de $\mathrm{CaCl}_{2}$ 2mM (Fig. 3a). Segundo Aguiar et al. 

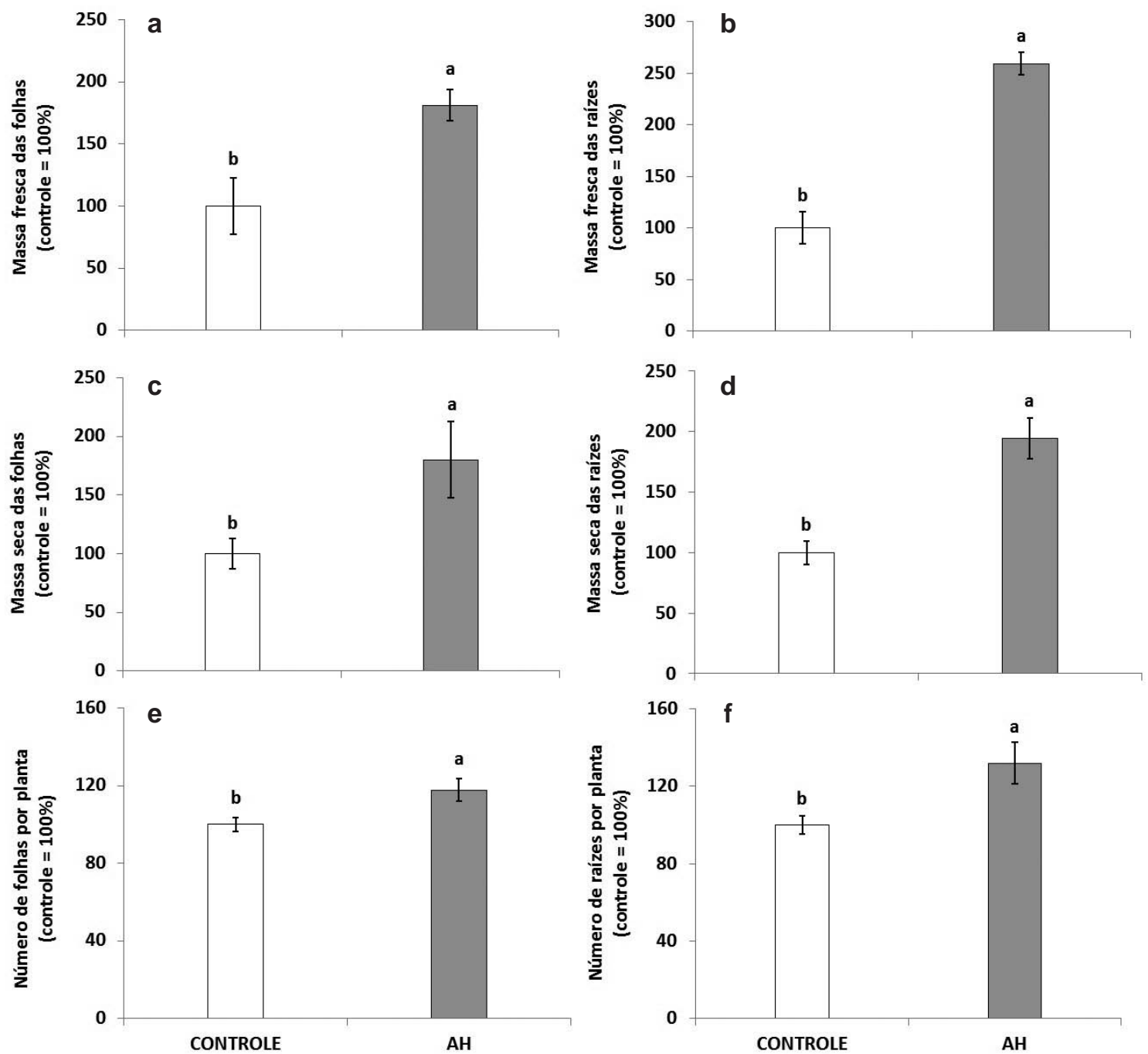

Figura 2 - Efeito dos ácidos húmicos $\left(4,16 \mathrm{mM} \mathrm{C} \mathrm{L}^{-1}\right)$ isolados de vermicomposto sobre a massa fresca das folhas (a); massa fresca radicular (b); massa seca das folhas (c); massa seca radicular (d) e número de folhas (e) e raízes (f) de plântulas de Cattleya warneri var. concolor. Os valores representam a média de 20 plantas \pm desvio padrão e foram normalizados em relação ao controle (controle=100\%). Médias seguidas de letras diferentes nas colunas são estatisticamente diferentes pelo Teste de Tukey $(p<0,05)$.

Figure 2 - Effect of humic acid (4.16 $\left.\mathrm{mM} \mathrm{C} \mathrm{L}^{-1}\right)$ isolated from vermicompost on the fresh weight of shoots (a); roots (b); dry weight of shoots (c) and roots (d) and number of leaves (e) and roots (f) of Cattleya warneri var. concolor seedlings. Values represent the mean of 20 plants \pm standard deviation and were normalized to the control (control $=100 \%$ ). Means followed by different letters in columns are statistically different by the Tukey test $(p<0.05)$.

(2011), o aumento da acidez do meio pode ser principalmente associado a dois fatores principais. $\mathrm{O}$ primeiro diz respeito à produção de $\mathrm{CO}_{2}$ pela respiração radicular, ou seja, durante a respiração há a produção de $\mathrm{CO}_{2}$ que ao se dissolver no meio causa redução do $\mathrm{pH}$ e o segundo devido aumento da extrusão de $\mathrm{H}^{+}$, possivelmente associado a atividade dos $\mathrm{AH}$ sobre as $\mathrm{H}^{+}$- ATPases.
Aguiar et al. (2013) afirmaram que apesar da acidez proporcionada pela exposição das plântulas aos AH não ser exclusivamente devido ao estímulo nas bombas de $\mathrm{H}^{+}$, possivelmente este método simplificado pode ser utilizado nos estudos de substâncias húmicas fisiologicamente ativas. Tais resultados ocorrem devido o mecanismo de promoção do crescimento celular ser mediado 


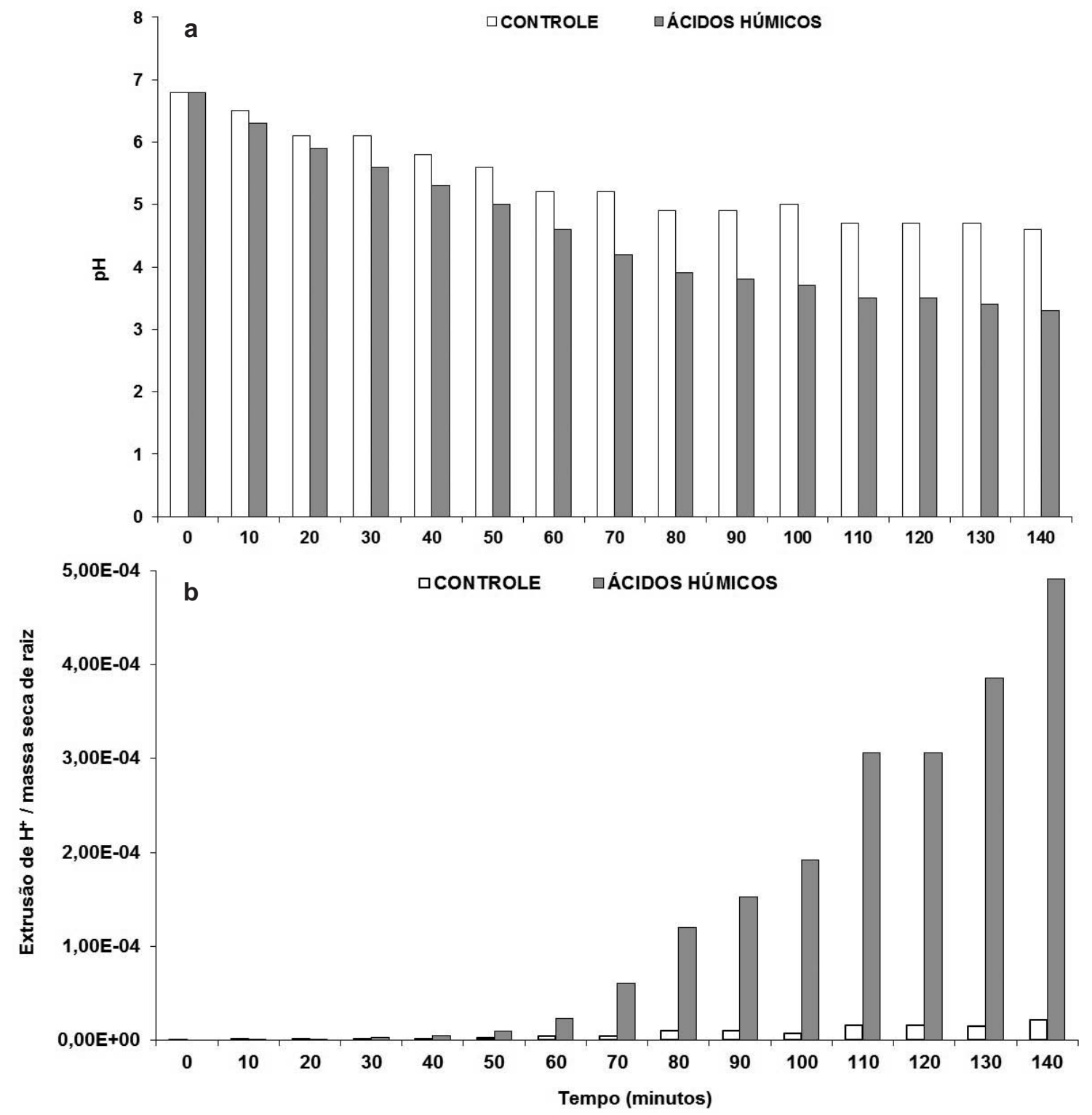

Figura 3 - a. Medida de pH da solução contendo plântulas de Cattleya warneri var. concolor após tratamento com a melhor dose de $\mathrm{AH}$ obtida no ensaio preliminar de dose resposta (4,16 mM C). b. Extrusão de $\mathrm{H}^{+}$pela massa seca de raízes de Cattleya warneri var. concolor após tratamento com a melhor dose de AH obtida no ensaio preliminar de dose resposta.

Figure 3 -a. Measurement of $\mathrm{pH}$ of solution containing seedlings of Cattleya warneri var. concolor after treatment with the best dose of HA obtained in the preliminary test dose response $(4.16 \mathrm{mM} \mathrm{C})$. b. Extrusion of $\mathrm{H}^{+}$by dry mass of Cattleya warneri var roots. concolor after treatment with the best HA dose obtained in the preliminary dose-response assay.

pelas $\mathrm{H}^{+}$-ATPases num processo conhecido como "a teoria do crescimento ácido" (Cordeiro et al. 2010). O processo de ativação das $\mathrm{H}^{+}$-ATPases que culmina com o alongamento celular se inicia com a geração do gradiente de $\mathrm{H}^{+}$e abaixamento do $\mathrm{pH}$, proporcionado pelo acúmulo de $\mathrm{H}^{+}$no lado externo à célula (Canellas \& Santos 2005).
Através dos dados obtidos (Fig. 3a,b) podese afirmar, pelo menos em parte, que a medida da acidez da solução contendo plantas tratadas com AH provavelmente está relacionada com a atividade da $\mathrm{H}^{+}$-ATPase (aumento da extrusão de $\mathrm{H}^{+}$) de membrana plasmática, uma vez que houve uma diminuição expressiva dos valores de $\mathrm{pH}$ das 
soluções de $\mathrm{CaCl}_{2}$ após o tratamento das plântulas de Cattleya warneri com os ácidos húmicos oriundos de vermicomposto, culminando com o crescimento radicular.

\section{Conclusões}

Os AH isolados de vermicomposto apresentaram capacidade de estimular o crescimento de plântulas de Cattleya warneri var. concolor crescidas in vitro e podem ser utilizados como uma ferramenta útil para o repovoamento dessa espécie em seu hábitat natural além de fornecer plantas com alto vigor vegetativo ao mercado mundial. Estabelece-se assim, um bioestimulante eficiente visando a produção de mudas de Cattleya warneri var. concolor.

\section{Agradecimentos}

À Fundação Nacional de Desenvolvimento do Ensino Superior Particular (FUNADESP) e a Fundação de Amparo à Pesquisa e Inovação do Espírito Santo (FAPES), a concessão de bolsas de estudos aos discentes do curso de Pós-graduação em Ecologia de Ecossistemas da Universidade Vila Velha e os recursos disponibilizados para a execução deste trabalho.

\section{Referências}

Ackerman, J.D. 1998. Evolutionary potential in orchids: patterns and strategy for conservation. Selbyana 19: 8-14.

Albanell, E.; Plaixats, J. \& Cabrero, T. 1988. Chemical changes during vermicomposting (Eisenia fetida) of sheep manure mixed with cotton industrial wastes. Biology and Fertility of Soils 6: 266-269.

Almeida, D.L. 1991. Contribuição da matéria orgânica na fertilidade do solo. Tese de Doutorado. Universidade Federal Rural do Rio de Janeiro, Seropédica. 188p.

Adani, F.; Genevini, P. \& Zaccheo, P. 1998. The effect of commercial humic acid on tomato plant growth and mineral nutrition. J. Plant Nutrition 21: 561-575.

Aguiar, N.O.; Canellas, L.P.; Dobss, L.B.; Zandonadi, D.B.; Olivares, F.L. \& Façanha, A.R. 2009. Distribuição de massa molecular de ácidos húmicos e promoção do crescimento radicular. Revista Brasileira Ciência Solo 33: 1613-1623.

Aguiar, N.O. 2011. Características químicas e bioatividade de ácidos húmicos isolados de vermicompostos em diferentes estádios de maturação. Dissertação de Mestrado. Universidade Estadual do Norte Fluminense - UENF, Campos dos Goytacazes. 86p. Disponível em <http://www.uenf.br/Uenf/Downloads/ PRODVEGETAL_3434_1328639584.pdf>. Acesso em 17 janeiro 2014.
Aguiar, N.O.; Olivares, F.L.; Novotny, E.H.; Dobbss, L.B.; Balmori, D.M.; Santos-Júnior, L.G.; Chagas, J.G.; Façanha, A.R. \& Canellas, L.P. 2013. Bioactivity of humic acids isolated from vermicomposts at different maturation stages. Plant Soil 362: 161-174.

Atiyeh, R.M.; Edwards, C.A.; Metzger, J.D.; Lee, S. \& Arancon, N.Q. 2002. The influence of humic acids derived from earthworm-processed organic wastes on plant growth. Bioresource Technology 84: 7-14.

Baldotto, M.A. \& Baldotto, L.E.B. 2014. Ácidos húmicos. Revista Ceres 61: 856-881.

Baldotto, L.E.B.; Baldotto, M.A.; Gontijo, J.B.; Oliveira, F.M. \& Gonçalves, J. 2014. Aclimatização de orquídea (Cymbidium sp.) em resposta à aplicação de ácidos húmicos. Ciência Rural 44: 830-833.

Bernardo, J.T.; Freitas, L.G.; Yamada, J.K.; Almeida, V.S.; Dallemole-Giaretta, R. \& Ferraz, S. 2011. Efeito de adubos orgânicos sobre Meloidogyne javanica em Tomateiro. Nematologia Brasileira 35: 10-19.

Canellas, L.P.; Santos, G.A. 2005. Humosfera - Tratado preliminar sobre a química das substâncias húmicas. L.P. Canellas e G.A. Santos, Campos de Goytacazes. 309p.

Canellas, L.P.; Olivares, F.L.; Korokova-Façanha, A.L. \& Façanha, A.R. 2002. Humic acids isoleted from earthworm compost enhance root elongation, lateral root emergence, and plasma membrane $\mathrm{H}^{+}$-ATPase activity in maize roots. Plant Physiology 130: 1951-1957.

Conceição, P.M.; Vieira, H.D.; Canellas, L.P.; Marques Júnior, R.B. \& Olivares, F.L. 2008. Recobrimento de sementes de milho com ácidos húmicos e bactérias diazotróficas endofíticas. Pesquisa Agropecuária Brasileira 43: 545-548.

Cordeiro, F.C.; Fernandes, M.S. \& Souza, S.R. 2010. Influência dos ácidos húmicos no metabolismo vegetal pode ser considerada uma resposta auxínica? Revista de Ciências da Vida 30: 111-131.

Dobbss, L.B.; Medici, L.O.; Pino Nunes, L.E.; Peres, L.E.P.; Rumjanec, V.M.; Façanha, A.R. \& Canellas, L.P. 2007. Changes in root development of Arabidopsis promoted by organic matter from oxisoils. Annals of Applied Biology 151:149-211.

Dobbss, L.B.; Canellas, L.P.; Olivares, F.L.; Aguiar, N.O.; Peres, L.E.P.; Azevedo,M.; Spaccini, R.; Piccolo, A. \& Façanha, A.R. 2010. Bioactivity of chemically transformed humic matter from vermicompost on plant root growth. Journal Agriculture Food Chemistry 58: 3681-3688.

Dorneles, L.T. \& Trevelin, V. 2011. Aclimatação e reintrodução de Cattleya intermedia Grahan ex Hook. (Orchidaceae) obtidas por propagação in vitro. Iheringia, Série Botânica 66: 167-174.

Elias, C.; De Nadai, F.E.A.; França, E.J. \& Bacchi, M.A. 2006. Seleção de epífitas acumuladora de 
elementos químicos na Mata Atlântica. Biota Neotropica 6: BN02106012006. Disponível em <http://www.scielo.br/scielo.php?pid=S167606032006000100010\&script $=$ sci_arttext $>$. Acesso em 3 fevereiro 2014.

Ferreira, D.F. 2011. SisVar®: Sistema de análise de variância para dados balanceados, versão 4.1. DEX/ UFLA, Lavras. (Software estatístico).

Fontana, A.; Brito, R.J.; Pereira, M.G.; Loss, A. \& Benites, V.M. 2010. Caracterização de substâncias húmicas da camada superficial do solo sob diferentes coberturas vegetais. Magistra 22: 49-56.

Martini, P.C.; Willadino, L.; Alves, G.D. \& Donato, V.M.T.S. 2001. Propagação de orquídea Gongora quinquenervis por semeadura in vitro. Pesquisa Agropecuária Brasileira 36: 1319-1324.

Miranda, C.C.; Canellas, L.P. \& Nascimento, M.T. 2007. Caracterização da matéria orgânica do solo em fragmentos de Mata Atlântica e em plantios abandonados de eucalipto. Revista Brasileira Ciência Solo 31: 905-916.

MMA. Ministério do Meio Ambiente. 2014. Instrução normativa $\mathrm{n}^{\circ} 6$, de 23 de setembro de 2008. Consultoria Jurídica. MMA, Brasília. 55p. Disponível em <http://www.mma.gov.br/ estruturas/179/_arquivos/179_05122008033615. pdf $>$. Acesso em 25 fevereiro 2014.

Nardi, S.; Pizzeghello, D.; Muscolo, A. \& Vianello, A. 2002. Physiological effects of humic substances on higher plants. Soil Biology \& Biochemistry 34: 1527-1536.

Nardi, S.; Muscolo, A.; Vaccaro, S.; Baiano, S.; Spaccini, R. \& Piccolo, A. 2007. Relationship between molecular characteristics of soil humic fractions and glycolytic pathway and Krebs cycle in maize seedlings. Soil Biology \& Biochemistry 39: 31383146.

Nikbakht, A.; Kafi, M.; Babalar, M.; Xia, Y.P.; Luo, A. \& Etemadi, N. 2008. Effect of humic acid on plant growth, nutrient uptake, and postharvest life of gerbera. Journal of Plant Nutrition 31: 2155-2167.

Pansarin, E.R. \& Pansarin, L.M. 2011. Reproductive biology of Trichocentrum pumilum: an orchid pollinated by oil-collecting bees. Plant Biology 13: 576-581.

Pinheiro, F.; Barros, F. \& Lourenço, R.A. 2004. O que é uma orquídea. In: Barros, F. \& Kerbauy, G.B. (eds.). Orquidologia sul-americana. Editora do Instituto de Botânica, São Paulo. Pp. 11-28.

Pinheiro, G.L.; Silva, C.A. \& Furtini Neto, A.E. 2010. Crescimento e nutrição de clone de eucalipto em resposta à aplicação de concentrações de C-ácidos húmicos. Revista Brasileira Ciência Solo 34: 1217-1229.

Ramos, A.C.; Dobbss, L.B.; Santos, L.A.; Fernandes, M.F.; Olivares, F.L.; Aguiar, N.O. \& Canellas, L.P. 2015. Humic matter elicits proton and calcium fluxes and signaling dependent on $\mathrm{Ca}^{2+-}$ dependent protein kinase (CDPK) at early stages of lateral plant root development. Chemical and Biological Technologies in Agriculture 2: 1-12.

Soares, J.D.R.; Araújo, A.G.; Pasqual, M.; Rodrigues, F.A. \& Assis, F.A. 2009. Concentrações de sais do meio Knudson $\mathrm{C}$ e de ácido giberélico no crescimento in vitro de plântulas de orquídea. Ciência Rural 2: 772-777.

Steelink, C. 1985. Implications of elemental characteristics of humic substances. In: Aiken, G. R.; Mcknight, D. M.; Wershaw, R. L. \& MacCarthy, P. (eds.). Humic substances in soil, sediments and water. Wiley Interscience, New York. Pp. 457-476.

Stevenson, F.J. 1994. Humus chemistry; genesis, composition, reactions. John Wiley \& Sons, New York. 496p.

Trevisan, S.; Pizzeghello, D.; Ruperti, B.; Francioso, O.; Sassi, A.; Palme, K.; Quaggiotti, S. \& Nardi, S. 2010. Humic substances induce lateral root formation and expression of the early auxinresponsive IAA19 gene and DR5 synthetic element in Arabidopsis. Plant Biology 12: 604-614.

Türkmen, Ö.; Dursun, A.; Turan, M.; Erdinç, Ç. 2004. Calcium and humic acid affect seed germination, growth, and nutrient content of tomato (Lycopersicon esculentum L.) seedlings under saline soil conditions. Acta Agriculturae Scandinavica 54: 168-174.

Vaughan, D. \& Malcolm, R.E. 1985. Influence of humic substances on growth and physiological processes. In: Vaughan, D. \& Malcolm, R.E. (eds.). Soil organic matter and biological activity. Martins Nijihoff Dr W. Junk Publisher, Dordrecht. Pp. 37-75.

Zandonadi, D.B.; Santos, M.P.; Busato, J.G.; Peres, L.E.P. \& Façanha, A.R. 2013. Plant physiology as affected by humified organic matter. Theoretical and Experimental Plant Physiology 25: 12-25.

Zanenga-Godoy, R. \& Costa, C.G. 2003. Anatomia foliar de quatro espécies do gênero Cattleya $L$ indl. (Orchidaceae) do Planalto Central Brasileiro. Acta Botânica Brasileira 17: 101-118.

Zeng, S.; Wu, K.; Silva, J.A.T.; Zhang, J.; Chen, Z.; Xia, N. \& Duan, J. 2012. Asymbiotic seed germination, seedling development and reintroduction of Paphiopedilum wardii Sumerh., an endangered terrestrial orchid. Scientia Horticulturae 138:198-209. 